\title{
Kuat Tekan Dan Tarik Beton Daur Ulang Yang Dibuat Dari Bongkaran Beton Perkerasan Kaku Jalan Sebagai Agregat Kasar: Studi Eksperimental
}

\author{
Suharwanto ${ }^{1}$, Komarudin ${ }^{1}$, Tarmizi Taher ${ }^{1}$ \\ ${ }^{1}$ Universitas Wiralodra, Jl. Ir. H. Juanda KM.03 Singaraja, Indramayu \\ *E-mail: suharwanto.ft@unwir.ac.id
}

\begin{abstract}
Recycled concrete is a mixture from recycled coarse or fine aggregate. One of them is made from demolished of road rigid pavement of concrete slab. It is coused by to damage, cracks and abrasion on the rigid pavement that is caused by vehicle loaded. The concrete demolished is often dumped in the any places or becomes fill material only. It has not benefited, so in this research, demolished of rigid pavement is made as a recycled aggregate. Utilization of this demolished concrete is a concrete material development, but it is not used commonly for rigid pavement material yet. Therefore, this research was use concrete demolished as raw material of concrete and it is tested experimentally to obtain the physical and mechanical properties of recycle concrete. Laboratory test result of water content percentage and specific gravity of recycled aggregate are smaller than natural aggregate or crush rock, but abrasion and water absorption or porosity percentage are greater than natural aggregate. Furthermore, the recycled aggregate is used as a substitute for natural coarse aggregate which variations of 0, 25, 50,75 and 100\%, and concrete compressive strength design is 20, 25 and $30 \mathrm{MPa}$. Result of the slump test as false The slump test as a kind of fresh concrete test does decrease when increasing the recycled aggregate content, that is $2-16, \%$. Likewise, decreasing of concrete weight volume is $0.88-9,28 \%$, concrete compressive test results us $3.7-25,7 \%$ and concrete tensile strength is $21,90-65,22 \%$. Those are caused by increasing abrasion and water absorption percentage of recycled aggregate.
\end{abstract}

Keywords: abrasion, normal aggregate, recycled aggregate, recycled concrete, slump

\begin{abstract}
Abstrak
Beton daur ulang merupakan campuran dari agregat kasar atau agregat halus daur ulang. Salah satunya dibuat dari hasil bongkaran pelat beton perkesaran kaku jalan (rigid pavement). Pembongkaran ini disebabkan oleh kerusakan, keretakan dan keausan pada perkerasan kaku yang diakibatkan oleh beban kendaraan. Bongkaran beton tersebut seringkali dibuang di sembarangan tempat atau hanya menjadi bahan urugan saja. Hal ini tidak menguntungkan, sehingga pada penelitian ini, bongkaran perkerasan kaku tersebut dijadikan sebagai agregat daur ulang. Pemanfaatan bongkaran beton ini merupakan perkembangan material beton, namun belum umum digunakan untuk material perkerasan kaku. Oleh karena itu, penelitian ini memanfaatkan bongkaran beton tersebut sebagai bahan baku beton dan diuji secara eksperimental untuk mendapatkan sifat fisik dan mekanik beton daur ulang. Hasil pengujian laboratorium menunjukkan bahwa persentase kadar air dan berat jenis agregat daur ulang lebih kecil dari agregat alam atau batu pecah, namun persentase abrasi dan penyerapan air atau porositas lebih besar dari pada agregat alam. Selanjutnya, agregat daur ulang tersebut digunakan sebagai pengganti agregat kasar alam dengan variasi $0,25,50,75$ dan $100 \%$, dan kuat tekan rencana beton 20, 25 dan 30 Mpa. Hasil uji slump sebagai salah satu jenis uji beton segar mengalami penurunan, karena adanya peningkatkan kandungan agregat daur ulang, yaitu $2,17-15,74 \%$. Begitu juga penurunan hasil uji berat volume yaitu $0.88-9,28 \%$, nilai kuat tekan beton adalah $3.7-25,7 \%$ dan tarik beton adalah $21,90-65,22 \%$. Hal ini diakibatkan oleh peningkatan nilai persentase abrasi dan penyerapan air pada agregat daur ulang.
\end{abstract}

Kata kunci: abrasi, agregat daur ulang, agrgat alam, beton daur ulang, slump. 


\section{Pendahuluan}

Beton merupakan material komposit yang tediri dari batu pecah (sebagai agregat kasar), pasir (sebagai agregat halus), semen dan air (sebagai bahan pengikat) [6]. Beton banyak digunakan untuk bahan konstruksi teknik sipil, seperti bangunan gedung, jembatan, jalan dan bagunan teknik sipil lainnya [14]. Hal ini akan mengakibatkan kebutuhan beton menjadi semakin banyak, sehingga berdampak pada kebutuhan batu pecah dan pasir semakin banyak yang akan berpengaruh pada peningkatan eksploitasi bahan tersebut. Pengaruh eksplotasi tersebut akan merusak lingkungan, oleh karena itu, perlu ada bahan alternatif pengganti agregat kasar dan halus pada beton. Salah satu alternative bahan penggantinya adalah agregat daur ulang. Beton yang dibentuk dari agregat daur ulang disebut Beton Daur Ulang (Recycled Concrete) [2 - 4].

Agregat daur ulang yang digunakan diperoleh dari bongkaran perkerasan kaku jalan yang umumnya dibuat dari beton. Bongkaran tersebut sering terjadi akibat adanya rusak, retak, atau aus akibat beban sumbu kendaraan dan gesekan roda kendaraan. Penggantian beton tersebut dilakukan dengan cara membongkar beton yang lama dan dicor ulang dengan beton yang baru, sehingga bekas bongkaran tersebut menimbulkan limbah beton yang umumnya dibuang di sembarang tempat atau hanya digunakan sebagai bahan urugan. Hal ini akan mengurangi kesuburan tanah, karena permukaan tanah tertutup oleh bongkahan beton, atau bahan yang tidak bermanfaat dan tidak ada nilai ekonomis.

Daur ulang yang digunakan untuk konstruksi jalan, umumnya pada saat ini adalah aspal, dimana lapisan aspal hotmix yang akan di-overlay (lapis tambahan) diperoleh dari kerukan aspal hotmix lama yang dibuat menjadi aspal hotmix kembali dengan menambah bahan aspal kembali sebagai bahan perekatanya [8].

Penggunaan bongkaran beton perkerasan jalan belum banyak digunakan dan diimplementasikan. Oleh karena itu, penggunaannya perlu dilakukan penelitian terlebih dahulu, sejauh mana kinerja dan kekuatan yang dihasilkan dari pemanfaaat material tersebut. Kinerja yang ditinjau adalah kuat tekan dan tariknya dan sering disebut sebagai sifat mekanik beton, karena kedua sifat mekanik tersebut merupakan dasar perencanaan untuk perkerasan kaku jalan [14 $-22]$.

Hal ini dikarenakan pelat beton tersebut sebagai pelat elastik yang diletakkan di atas permukaaan tanah. Permukaan tanah tersebut sering diasumsikan sebagai pondasi elastik pada saat melakukan perencanaan. Dengan demikian, pelat beton tersebut akan menerima tegangan tekan pada permukaan atas dan tegangan tarik pada permukaan bawah. Oleh karena itu, kedua komponen kinerja tersebut sangat penting untuk perencanaan. Disamping itu, pelat perkerasan kaku ini pada umumnya mempunyai rasio atau perbadingan luas penampang besi dan beton sangat kecil dan bahkan banyak pelat beton perkerasan kaku jalan tidak menggunakan tulangan, sehingga komponen kinerja tersebut di atas menjadi sangat penting.

Fenomena pemanfaatan bekas bongkaran jalan sebagai bahan agregat kasar merupakan terobosan baru dan inovasi baru sebagai perkembangan material beton. Penelitian ini diperlukan, karena penelitian yang sejenis belum banyak dilakukan, dan pada umumnya adalah agregat reruntuhan bangunan gedung yang digunakan untuk pengganti agregat (halus dan kasar) yang kemudian digunakan untuk bahan bangunan gedung lagi, sebagai bahan lantai dan dinding [14].

Demikian juga pada penelitian sebelumnya dengan memanfaatkan beton daur ulang sebagai bahan baku pembuatan balok dan kolom. Hal ini masih adanya kekhawatiran akan kinerjanya. Oleh karena itu, penelitian lanjutan perihal daur ulang masih banyak dilakukan untuk lebih mengetahui kinerja dan pengaruhnya terhadap elemen struktur tersebut. 


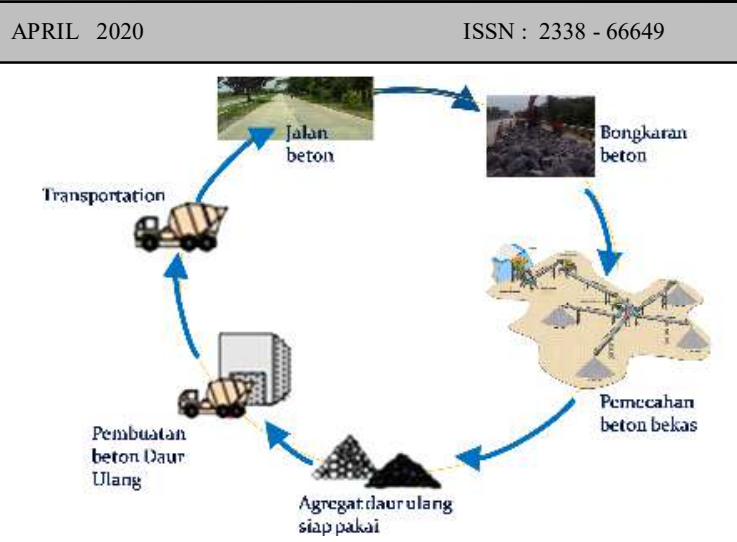

\section{Metodologi}

Penelitian ini dilakukan beberapa tahap, dari mulai penyiapan dan pengujian kualitas bahan baku pembentuk beton (semen, air, pasir, batu becah, bongkaran beton bekas perkerasan kaku), perhitungan perencanaan campuran beton yang mengikuti Standar Nasional Indoensia atau SNI [15], peralatan untuk membuat beton dan pengujian di laboratorium (pengujian beton segar atau adukan beton dan beton setelah mengeras), dan analisa data untuk mendapatkan tujuan penelitian, yaitu mengetahui kinerjanya. Adapun langkah-langkah tersebut di atas dapat digambarkan pada diagram alir dapat dilihat pada Gambar 1. Sedangkan proses pembuatan agregat daur ulang dapat dilihat pada Gambar 2.

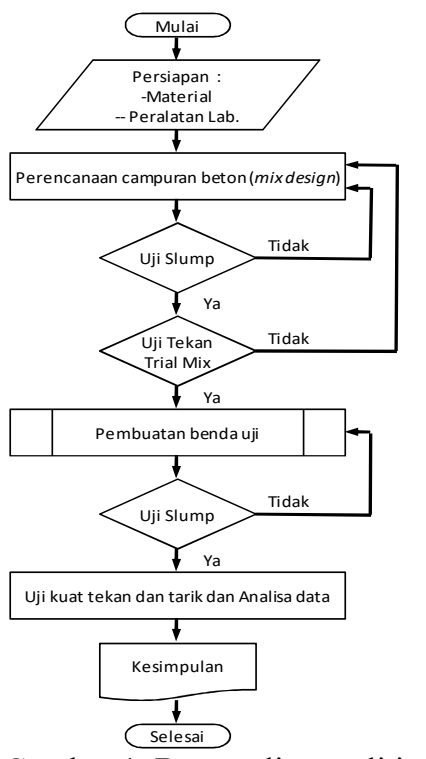

Gambar 1. Bagan alir penelitian

Gambar 2. Proses pembuatan agregat daur ulang dari bongkaran perkerasan kaku jalan raya

Berdasarkan pada Gambar 1 (Bagan Alir) di atas, dimulai dari penyiapan dan pembuatan agregat daur ulang yang diperloeh dari bongkaran perkerasan jalan kaku (seperti pada Gambar 2). Pada proses pembuatan agregat daur ulang tersebut dimulai dari pengumpulan hasil bongkaran beton, kemudian dipecahkan dan dipisah-pisah berdasarkan besaran buritan, seperti halnya pada proses pemecahan batu (crushing), baru kemudian dapat dijadikan sebagai agregat daur ulang dan dapt digunakan sebagai bahan baku pembuat beton.

Dalam penelitian ini, agregat daur ulang yang digunakan hanya agregat kasarnya saja. Bahan baku pembentuk beton tersebut di atas dilakukan uji kualitas terlebih dahulu agar material yang digunakan memenuhi spesifikasi yang disyaratkan pada SNI [14 22]. Uji material tersebut meliputi uji persentase kadar lumpur, kadar air, penyerapan, dan lainnya. Selanjutnya dibuat perencanaan campuran (mix design) beton untuk mendapatkan jumlah bahan baku pembentuk beton sesuai dengan porsinya. Lalu dilakukan uji slump dan trial mix agar komposisi dari perencanaan tersebut menghasilkan nilai kuat tekan yang diharapkan.

Kemudian dibuat benda uji beton yang dimensinya adalah diameter $150 \mathrm{~mm}$ dan panjang $300 \mathrm{~mm}$ (sesuai standar uji mekanik yang telah diatur di SNI [20]). Benda uji yang dibuat sebanyak lebih dari dari 300 buah dengan vasiasi persentase kandungan agregat daur ulang dari muali $0 \%, 25 \%, 50 \%, 75 \%$ 
dan $100 \%$, dan variasi kuat tekan 20, 25, dan $30 \mathrm{MPa}$ yang diuji pada umur beton 3, 7, 17, 21, dan 28 hari. Namun untuk uji kuat tarik dilakukan hanya pada umur 28 hari saja, karena mengikuti standar SNI $[17,21]$. Hasil uji mekanik terhadap beberapa benda uji tersebut dimaksudkan untuk mendapat nilai kuat tekan dan tarik beton sebagai indikator kinerja beton.

Data yang diperoleh dari hasil ekperimental tersbeut di atas dilakukan analisa data untuk mendapatkan perbandingan kinerja beton yang menggunakan agregat batu pecah yang dari alam dan yang dibuat dari daur ulang dengan beberapa persentase variasi kandunagn agregat daur ulang tersebut di atas.

\section{Hasil dan Pembahasan}

Penelitian ekperimantal yang telah dijelaskan pada metodologi tersebut di atas dibuat tabel dan gambar grafik agar lebih jelas dan sistematis. Analisa dilakukan mulai dari uji kualitas material hingga uji kinerja beton yang akan dijelaskan secara rinci di bawah ini.

\section{1. Uji Material Pembentuk Beton}

Uji material meliputi ini meliputi uji fisik dan kimia, serta uji gradasi atau penyebaran butiran agregat halus dan kasar yang akan ditampilkan dalam bentuk tabel dan grafik. Hasil uji fisik dan kimia bahan baku pembentuk beton berupa semen dan agregat kasar \& halus dicantumkan di dalam Tabel 1. Sedangkan hasil uji gradasi agregat halus dan kasar digambarkan pada Gambar 3.a dan 3.b.

Berdasarkan tabel tersebut di atas ternyata agregat daur ulang mempunyai nilai persentase kadar air dan berat jenis yang lenih kecil, namun memiliki nilai persentase abrasi (persentase kehancuran butiran) dan penyerapan air (prositas) yang lebih besar bila dibandingkan dengan agregat alam atau batu becah. Sedangkan hasil uji gradasi dari kedua jenis material tersebut memenuhi persyaratan SNI, sehingga keduanya dapat digunakan sebagai bahan baku pembuatan beton.

Tabel 1. Hasil Uji bahan baku pembentuk beton a. Uji sifat fisik dan kimia Semen Portland Tipe 1

\begin{tabular}{lr}
\hline \multicolumn{1}{c}{ Parametern Pengujian } & Hasil Uji \\
\hline Kehalusan (SSA), $\mathrm{cm}^{2} / \mathrm{gr}$ & 2910 \\
Waktu pengikatan awal, menit & 141 \\
Waktu pengikatan akhir, menit & 285 \\
Alkalis $\left(\mathrm{Na}_{2}+\mathrm{K}_{2} \mathrm{O}\right), \%$ & 0,00 \\
Hilang pijar, \% & 0,90 \\
Spesific gravity & 3,15 \\
Angka kehalusan & 1,16 \\
$\mathrm{SiO}_{2}, \%$ & 21,20 \\
$\mathrm{Al}_{2} \mathrm{O}_{3}, \%$ & 6,00 \\
$\mathrm{Fe}_{2} \mathrm{O}_{3}, \%$ & 3,10 \\
$\mathrm{CaO}_{2} \%$ & 64,90 \\
$\mathrm{MgO}, \%$ & 1,20 \\
&
\end{tabular}

b. Uji sifat fisik agregat halus dan kasar

\begin{tabular}{lrr}
\hline \multicolumn{1}{c}{ Jenis Pengujian } & $\begin{array}{c}\text { Agregat } \\
\text { Alam }\end{array}$ & $\begin{array}{c}\text { Agregat } \\
\text { Daur } \\
\text { Ulang }\end{array}$ \\
\hline Agregat Halus & & \\
\hline Apparent specific gravity & 2,808 & \\
Bulk specific gravity (kering) & 2,245 & \\
Bulk specific grafity (SSD) & 2,445 & \\
\% absorpsi air & 5,490 & \\
Berat volume padat (kg/ltr) & 1,558 & \\
Berat volume gembur (kg/ltr) & 1,395 & \\
Kadar lumpur (\%) & 2,500 & \\
Angka kehalusan & 3,114 & \\
Kadar air (\%) & 12,300 & \\
Soundness (\%) & 7,600 & \\
\hline Agregat Kasar & & \\
\hline Apparent specific gravity & 2,701 & 2,710 \\
Bulk specific gravity (kering) & 2,314 & 2,172 \\
Bulk specific gravity (SSD) & 2,457 & 2,374 \\
\% absorpsi air & 2,870 & 8,512 \\
Berat volume padat (kg/ltr) & 1,409 & 1,302 \\
Berat volume gembur (kg/ltr) & 1,284 & 1,111 \\
Agregat maksimum (mm) & 20,000 & 10,000 \\
Kadar lumpur (\%) & 0,500 & 0,100 \\
Kadar air (\%) & 7,001 & 4,312 \\
Angka kehalusan & 6,560 & 7,430 \\
Angka keausan (abrasi) (\%) & 17,600 & 23,400 \\
Soundness (\%) & 2,179 & 6,000 \\
Alkali rektif & Nil & Nil \\
\hline & & \\
\hline
\end{tabular}

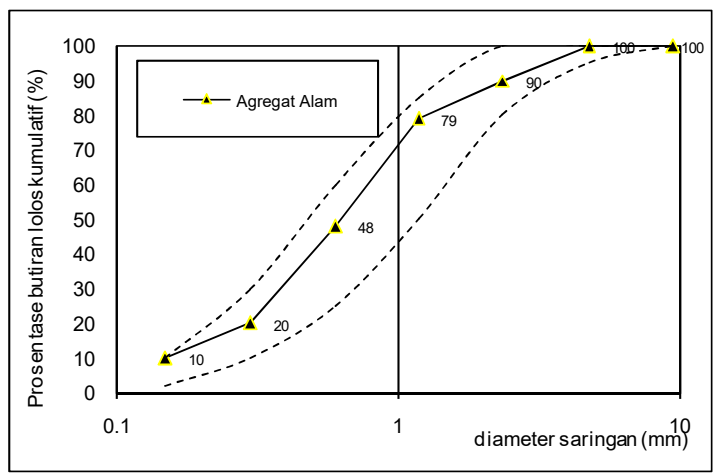

a. Kurva gradasi agregat halus 


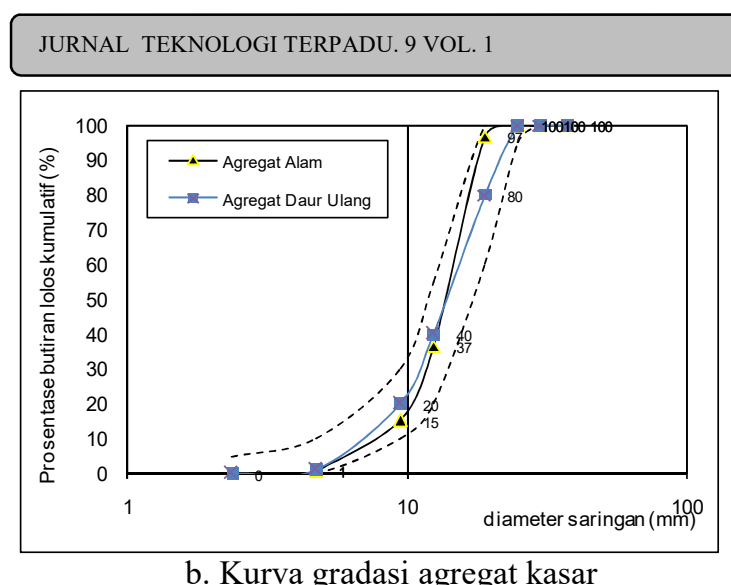

Gambar 3. Kurva gradasi agregat halus dan kasar

\section{2. Uji Beton Segar (Adukan Beton)}

Uji beton segar meliputi uji slump atau kelecakan beton dapat dilihat pada Gambar 4. Uji slump ini merupakan indicator untuk kelecakan beton segar agar mudah untuk pengerjaan pengecoran beton. Apabila beton terlalu kaku atau keras karena kekurangan air atau sebaliknya yang terlalu encer, maka sulit untuk dicetak. Oleh karena ada aturan SNI [19] nilai slumpnya yaitu antara $75 \mathrm{~mm}$ hingga $120 \mathrm{~mm}$.

Berdasarkan Gambar 4 tersebut di atas, nilai kandungan persentase agregat daur ulang di dalam beton mempunyai nilai slump semakin kecil. Hal ini seiring dengan nilai penerapan air atau porositas pada agregat daur ulang yang lebih besar dari pada agregat alam atau batu pecah, sehingga air campuran beton akan lebih banyak terserap ke dalamnya dan adukan beton menjadi lebih kering bila dibandingkan dengan beton yang dibuat dari agregat alam. Namun nilai slump tersebut masih dalam pengaturan SNI [19] yang disebut di atas. Dengan demikian, beton daur ulang tersebut masih memenuhi syarat. Besarnya persentase penurunan nilai slump adalah $6,48-15,74 \%$ untuk beton mutu 20 $\mathrm{MPa}, 2,17$ - 11,96\% untuk beton mutu 25 $\mathrm{MPa}$ dan 5,56 - 11,11\% untuk beton mutu 30 $\mathrm{MPa}$. Hasil ini mirip dengan hasil penelitian sebelumnya [1 - 10] yang juga ada penuruan nilai berat volume beton dan umunya penurunan tersebut hingga $15 \%$.

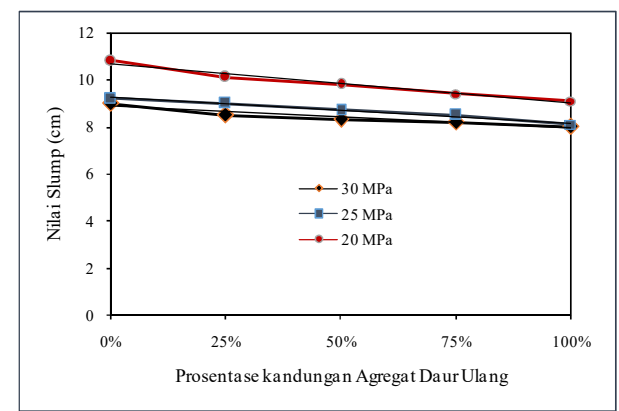

Gambar 4. Kurva hubungan antara persentase kandungan agregat daur ulang dan nilai slump.

\section{3. Uji Beton Keras (Kuat Tarik dan Tekan)}

Uji beton keras meliputi uji berat volume, kuat tekan dan kuat tarik beton. Uji berat volume dimaksudkan untuk mengetahui tingkat berat dari material beton. Uji berat volume ini ditunjukan pada Tabel 2 di bawah ini.

Tabel 2. Hasil Uji berat volume beton

\begin{tabular}{|c|c|c|c|}
\hline $\begin{array}{c}\text { Persentase } \\
\text { Kandunagn } \\
\begin{array}{c}\text { Agregat } \\
\text { Daur Ulang }\end{array}\end{array}$ & \multicolumn{3}{|c|}{$\begin{array}{c}\text { Nilai Berat Volume Beton } \\
\text { (kg/m3) }\end{array}$} \\
\cline { 2 - 4 } & $\mathbf{2 0} \mathbf{~ M P a}$ & $\mathbf{2 5} \mathbf{~ M P a}$ & $\mathbf{3 0}$ MPa \\
\hline 0 & 2361 & 2367 & 2374 \\
\hline 25 & 2319 & 2336 & 2353 \\
\hline 50 & 2266 & 2281 & 2287 \\
\hline 75 & 2244 & 2258 & 2265 \\
\hline 100 & 2142 & 2166 & 2219 \\
\hline
\end{tabular}

Berdasarkan tabel tersebut di atas, nilai berat volume beton agregat daur ulang lebih kecil dari pada beton agreget alam, dan semakin besar persentase kandungan agregat daur ulang, maka nilai berat volume semakin kecil. Hal ini diakibatkan oleh nilai berat jenis agregat daur ulang yang lebih kecil dari pada agregat alam. Disamping itu, porositas agregat daur ulang yang lebih besar menyebabkan ringga udara yang ada di dalam beton menjadi lebih banyak, sehingga beton yang dibentuknya menjadi lebih ringan. Besarnya penurunan nilai berat volume adalah 1.78 $9,28 \%$ untuk beton mutu $20 \mathrm{MPa}, 1,31$ $8,49 \%$ untuk beton mutu $25 \mathrm{MPa}$ dan $0,88-$ $6,53 \%$ untuk beton mutu $30 \mathrm{MPa}$. Hasil ini seiring dengan hasil penelitian sebelumnya [1 - 10] yang juga ada penuruan nilai berat 
volume beton dan umunya penurunan tersebut hingga $10 \%$.

Uji beton keras lainnya adalah kuat tekan beton. Uji kuat tekan ini dilakukan pada umur 3, 7, 14, 21, dan 28 hari [16, 20]. Hal ini dimaksudkan untuk meninjau perkembangan nilai kuat tekan beton, dimana peningkatan kuat tekan beton seiring dengan proses reaksi hidrasi yang terjadi. Pada usia muda reaksi hidrasi belum sempurna dan semakin bertambahnya umur, reaksi hidrasi tersebut semakin sempurna. Uji kuat tekan beton tersebut dapat dilihat pada Gambar 5 di bawah ini.

Berdasarkan kurva pada Gambar 5 tersebut dapat dilihat bahwa semakin bertambahnya umur, maka nilai kuat tekan semakin bertambah. Umur 28 hari merupakan puncak nilai uji tekan, karena reaksi hidrasi pada umur 28 hari telah sempurna dan nilai uji tekan pada umur 28 hari dapat dilihat pada Gambar 6.

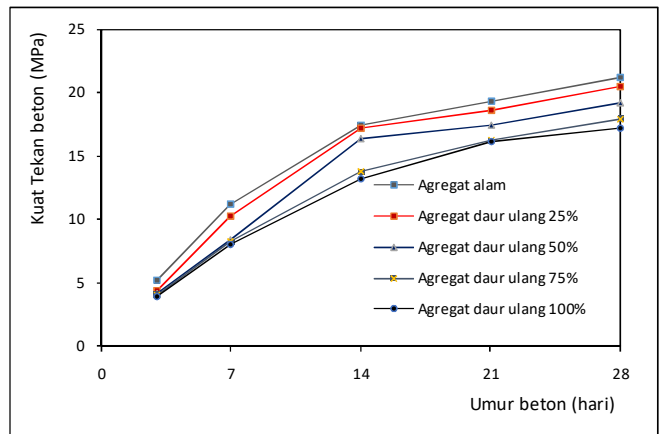

a. Kurva perkembangan kuat tekan beton $20 \mathrm{MPa}$

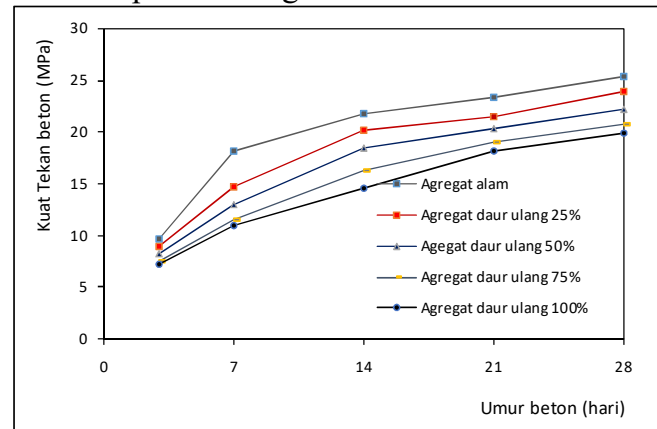

b. Kurva perkembangan kuat tekan beton $25 \mathrm{MPa}$

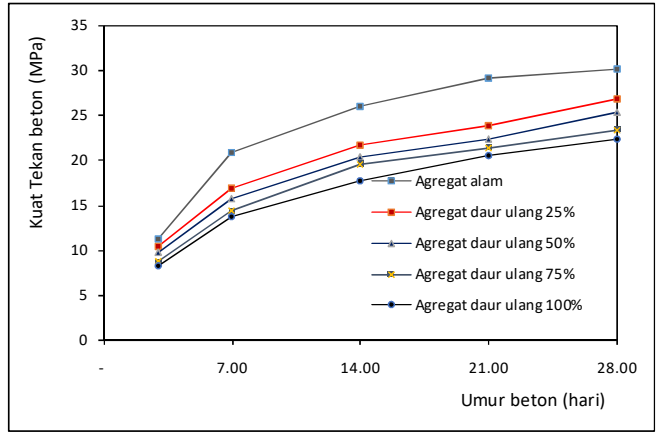

c. Kurva perkembangan kuat tekan beton $30 \mathrm{MPa}$ Gambar 5. Kurva hubungan antara umur dan kuat tekan beton.

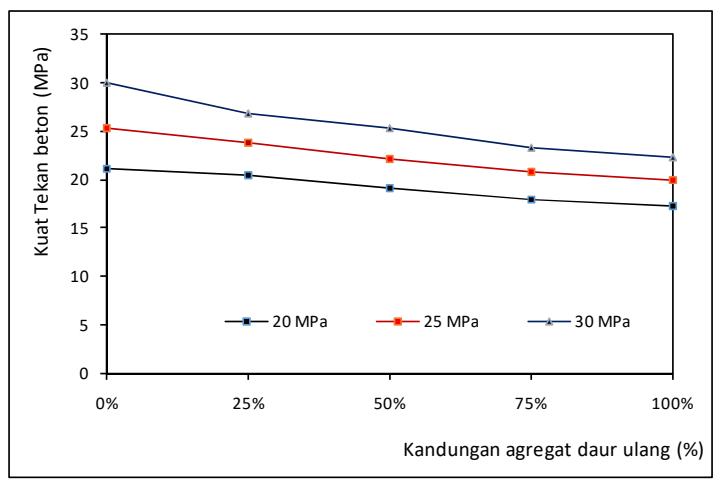

Gambar 6 Kurva hubungan antara persentase kandunagn agregat daur ulang dan kuat tekan beton.

Apabila ditinjau Gambar 6 tersebut di atas dari persentase variasi jumlah agregat daur ulang di dalam beton, maka nilai kuat tekan semakin menurun. Hal ini seiring dengan penurunan kualitas agregat daur ulang yang ditunjukan oleh nilai abrasi yang lebih besar dari pada agregat alam, serta nilai porositas yang lebih besar. Dengan demikian, pengaruh penurunan kualitas agregat daur ulang tersebut akan meurunkan nilai kuat tekan beton, karena pengaruh nilai kekuatan dan porositas bahan bakunya. Besarnya nilai persentase penurunan nilai kuat tekan adalah $3.7-18,7 \%$ untuk beton mutu $20 \mathrm{MPa}, 5,7-$ $21,2 \%$ untuk beton mutu $25 \mathrm{MPa}$ dan 10,7 $25,7 \%$ untuk beton mutu $30 \mathrm{MPa}$. Hasil pada penelitian sebelumnya [1 - 10] yang juga ada penuruan nilai berat kuat tekan beton dan hingga $26 \%$ untuk beton mutu normal.

Berdasarkan penurunan nilai kuat tekan, maka perencanaan pelat beton perkerasan kaku akan mempunyai nilai reduksi yang semakin besar. Pada penelitian ini, nilai 
reduksi perencanaan belum diperoleh, karena harus dilakukan penelitian lanjutan terhadap pelat perkerasan kaku secara sekala penuh (full scale). Nilai reduksi tersebut juga merupakan nilai keamanan perencanaan struktur.

Uji beton keras selanjutnya adalah uji tarik beton. Uji tarik yang dilakukan adalah uji tarim tidak langsung, yaitu dengan cara belah atau sering disebut splitting test. Uji ini berdasarkan pada aturan SNI [14, 18]. Hal ini dilakukan, karena sulitnya membuat benda uji tarik langsung pada beton dan juga alat uji tariknya. Prinsip uji tarik belah ini adalah dengan membelah benda uji dengan mesin uji tekan, dimana efek belah tersebut meberikan tarikan pada material beton, seperti yang ditunjukan pada Gambar 7 di bawah ini.

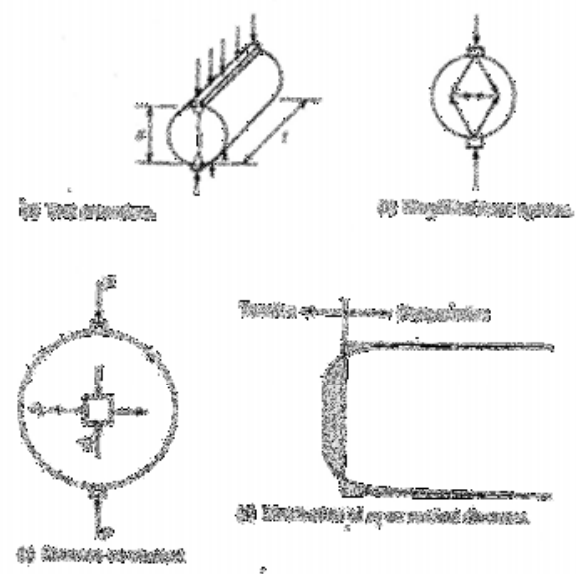

Gambar 7. Fenomena uji tarik belah beton silinder.

Sedangkan hasil uji tarik tidak langsung beton dapat dilihat pada Gambar 8 di bawah ini.

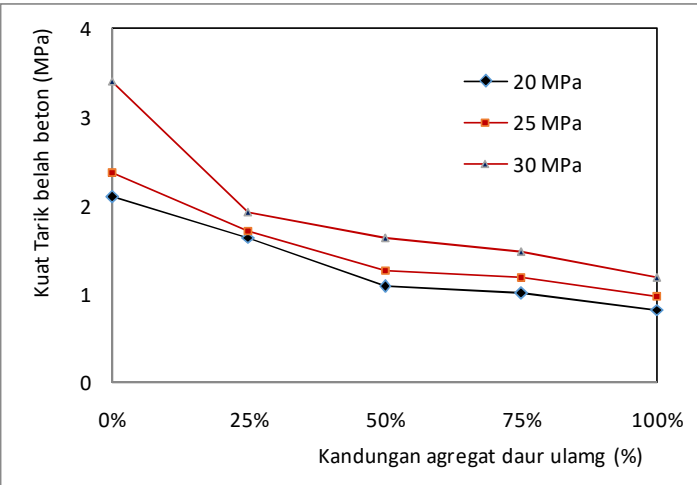

Gambar 8. Kurva hubungan antara persentase kandunagn agregat daur ulang dan kuat tarik belah beton.

Berdasarkan gambar kurva tersebut dari persentase variasi jumlah agregat daur ulang di dalam beton, maka nilai kuat tarik semakin menurun. Hal ini juga diakibatkan oleh nilai penurunan kualitas agregat daur ulang yang ditunjukan oleh nilai abrasi yang lebih besar dari pada agregat alam, serta nilai porositas yang lebih besar. Dengan demikian, nilai kuat tarik beton juga akan menurun. Besarnya nilai persentase penurunan kuat tarik adalah 21,90 - 60,95\% untuk beton mutu $20 \mathrm{MPa}, 28,13$ $59,38 \%$ untuk beton mutu $25 \mathrm{MPa}$ dan 43,48 $-65,22 \%$ untuk beton mutu $30 \mathrm{MPa}$.

Berdasarkan penurunan nilai kuat tarik tersbeut, maka perencanaan pelat beton perkerasan kaku juga akan mempunyai nilai reduksi yang semakin besar. Penelitian lanjutan perlu dilakukan, karena pada penelitian ini, nilai reduksi perencanaan belum diperoleh, karena harus dilakukan penelitian lanjutan terhadap pelat perkerasan kaku secara sekala penuh (full scale).

\section{Kesimpulan}

Penelitian yang telah dilakukan di atas dapat disimpulkan sebagai berikut:

1. Agregat daur ulang yang dibuat dari bekas bongkaran pelat beton perkerasan kaku memiliki nilai persentase kadar air dan berat jenis yang lenih kecil, namun memiliki nilai persentase abrasi (persentase kehancuran butiran) dan penyerapan air (prositas) yang lebih besar bila dibandingkan dengan agregat alam atau batu becah.

2. Hasil uji gradasi dari kedua jenis material tersebut memenuhi persyaratan SNI, sehingga keduanya dapat digunakan sebagai bahan baku pembuatan beton

3. Nilai kandungan persentase agregat daur ulang di dalam beton berpengaruh pada nilai slump, dimana nilai slump yang dihasilkan semakin kecil. Hal ini seiring dengan nilai penyerapan air atau porositas pada agregat daur ulang yang lebih besar 
dari pada agregat alam atau batu pecah. Besarnya persentase penurunan nilai slump adalah 2,17 - 15,74\%.

4. Besarnya nilai persentase variasi jumlah agregat daur ulang di dalam beton, mengakibatkan nilai berat volume, kuat tekan dam kuat tarik semakin menurun, karena adanya penurunan kualitas, peningkatan porositas dan abrasi agregat daur ulang. Besarnya penurunan persentase nilai berat volume adalah $0,88-9,28 \%$, sedangkan persentase penurunan nilai kuat tekan adalah 3,7 - 25,7\%.

5. Nilai persentase variasi jumlah agregat daur ulang di dalam beton yang semakin besar menyebabkan nilai kuat tarik semakin menurun, karena adanya penurunan kualitas agregat daur ulang. Besarnya persentase nilai penurunan kuat tarik adalah 21,90-65,22\%.

\section{Saran}

Penelian lanjutan diperlukan secara skala penuh terhadap pelat beton perkerasan kaku untuk mengetahui kinerja pelat beton tersebut dan nilai reduksi perencanaannya.

\section{Daftar Pustaka}

[1] Foster, S. W., "Recycled Concrete as Aggregate", ACI Concrete International, Volume 8, Issue 10, pp. 34-40, October 1986

[2] Hamid, DA, As'ad, A., Safitri, E, "Pengaruh Penggunaan Agregat Daur Ulang Teerhaadap Kuat Tekan dan Modulus Elastisitas Beton berkinerha Tinggi Grade 80", e-Jurnal MATRIKS TEKNIK SIPIL Vol. 2 No. 2/Juli 2014/43, ISSN 2354-8630.

[3] Han A. L., "Concrete Recycling". Media Komunikasi Teknik Sipil, vol. 14, no. 2, pp. 198-205, Juni 2006

[4] Hansen, T. C. and Lauritzen, E. K., "Concrete Waste in Global Perspective". ACI Special Publication SP- 219 - 3, Volume 219, pp. 35-46, March 2004

[5] Mehta, P. K., 2001, "Reducing the Environmental Impact of Concrete", ACI Concrete International, Volume 23, Issue 10, pp. 61-66, , Page 24-28, October 2001.
[6] Rashwan, M. S. and AbouRizk, S., 1997, "The Properties of Recycled Concrete, Factor affecting strength and workability". ACI Concrete International, Volume 19, Issue 7, pp. 56-60, July 1997.

[7] Shayan, A. and Xu, A., "Performance and Properties of Structural Concrete Made with Recycled Concrete Aggregate" ACI Material Journal, Volume 100, Issue 5, pp. 371-380, September-October 2003.

[8] Sutan, S.A, Sahib, B., , "Improvement of Rigid Pavement Containing Recycled Concrete Aggregate", Pavement Engineering and road materials Journal, August 2017.

[9] Tavakoli, M. and Soroushian, P., "Strength of Recycled Aggregate Concrete Made Using Field-Demolished Concrete as Aggregates" ACI Material Journal, Volume 93, Issue 2, pp. 178-181, April 1996.

[10] Zaumanis, M., Mallick, R. B., \& Frank, R., " $100 \%$ recycled hot mix asphalt: A review and analysis". Resources, Conservation and Recycling 92, International Journal of Sustainable Resource Management and Environmental Efficency, , pp. 230-245, July 2014.

[11] Jindal, A., Ransinchung, G. D. R.N., Kumar, P. , 2014, "Recycled Concrete Aggregates for Rigid Pavements: A review', Conference: International Conference on Sustainable Civil Infrastructure (ICSCI)

[12] Kasai, Y. and Fujii, T., 1988, "Demolition and Reuse of Concrete and Masonry". Highlights of the Second RILEM Proceedings 23, Third International Symposium in Tokyo, ACI Concrete International, Volume 11, Issue 3, pp.

[13] Neville, A.M., 2011, "Properties of Concrete". Pearson Education Limited, Essex.

[14] SNI 03 2847:2002. "Tata Cara Perhitungan Struktur Beton untuk Bangunan Gedung". Jakarta: Badan Standarisasi Nasional

[15] SNI 03-1750:1990, "Mutu dan Cara Uji Agregat Beton". Jakarta: Badan Standarisasi Nasional.

[16] SNI 03-1974:1990. "Metode Pengujian Kuat Tekan Beton". Jakarta: Badan Standarisasi Nasional

[17] SNI 03-2491:2002. "Metode Pengujian Kuat Tarik Belah Beton". Jakarta: Badan Standarisasi Nasional 
[18] SNI 1970:2008. "Cara Uji Berat Jenis dan Penyerapan Air Agregat Halus”. Jakarta: Badan Standarisasi Nasional

[19] SNI 1972:2008. "Cara Uji Slump Beton". Jakarta: Badan Standarisasi Nasional

[20] SNI 1974:2011. "Cara Uji Kuat Tekan Beton dengan Benda Uji Silinder". Jakarta: Badan Standarisasi Nasional.

[21] SNI 2491:2014. "Metode Uji Kekuatan Tarik Belah Spesimen Beton Silinder". Jakarta: Badan Standarisasi Nasional

[22] SNI 7064:2014, "Semen Portland Komposit". Jakarta: Badan Standarisasi Nasional. 